\title{
IL-13 mRNA tissue content identifies two subsets of adult ulcerative colitis patients with different clinical and mucosa-associated microbiota profiles
}

Alessia Butera ${ }^{1}$, Monica Di Paola ${ }^{2}$, Francesco Vitali ${ }^{3}$, Daniela De Nitto ${ }^{4}$, Francesco Covotta ${ }^{5}$, Francesco Borrini ${ }^{6}$, Roberta Pica ${ }^{4}$, Carlotta De Filippo ${ }^{3}$, Duccio Cavalieri ${ }^{2}$, Alessandro Giuliani ${ }^{7 \S}$, Annamaria Pronio ${ }^{5 \S}$, Monica Boirivant ${ }^{1 \S}$

1 Istituto Superiore di Sanità, National Center for Drug Research and Evaluation, Rome, Italy, ${ }^{2}$ Department of Biology, University of Florence, Firenze, Italy, ${ }^{3}$ Institute of Agricultural Biology and Biotechnology, National Research Council, Pisa, Italy, ${ }^{4}$ Sandro Pertini Hospital, IBD, GE Unit, Rome, Italy, "University "Sapienza”, Dept General Surgery, "P. Stefanini”, Rome, Italy, ${ }^{6}$ Sandro Pertini Hospital, UOC Pathology Section, Rome, Italy, ${ }^{7}$ Istituto Superiore di Sanità, Dept Environment and Health, Rome, Italy

$\S$ Authors share co-senior authorship.

Contact details: Alessia Butera: alessia.butera@iss.it, Monica Di Paola: monica.dipaola@unifi.it, Francesco Vitali: francesco.vitali.bio@gmail.com, Daniela De Nitto: denittod@hotmail.com, Francesco Covotta: francesco.covotta@gmail.com, Francesco Borrini: francesco.borrini@aslroma2.it, Roberta Pica: roberta.pica@aslroma2.it, Carlotta De Filippo: carlotta.defilippo@ibba.cnr.it, Duccio Cavalieri: duccio.cavalieri@unifi.it, Alessandro Giuliani: alessandro.giuliani@iss.it, Annamaria Pronio: annamaria.pronio@uniroma1.it

\section{Corresponding Author:}

Monica Boirivant, MD

National Center for Drug Research and Evaluation

Istituto Superiore di Sanità

Viale R. Elena, 299

00161 Roma

ITALY

Phone:+390649902976

e-mail:

This study was presented in part to the DDW 2018 Washington DC. USA 


\section{ABSTRACT}

Background and Aim. A personalized approach to therapy has great promise to improve disease outcomes. To this end, the identification of different subsets of patients according with the prevalent pathogenic process might guide in the choice of therapeutic strategy. We hypothesize that UC patients might be stratified according to distinctive cytokine profiles and/or to a specific mucosa-associated microbiota Methods. In a cohort of clinically and endoscopic active UC patients and controls, we analyzed by qPCR the mucosal cytokine mRNA content and the mucosa-associated microbiota composition assessed by the 16SrRNA gene sequencing. Results. We demonstrate, by means of datadriven approach, the existence of a specific UC patient subgroup characterized by elevated IL13mRNA tissue content separated by patients with low IL-13 mRNA tissue content. The two subsets differ in clinical-pathological characteristics. High IL-13mRNA patients are younger at diagnosis and show higher prevalence of extensive colitis than low IL-13mRNA ones. They also show a more frequent use of steroid/immunosuppressant/anti-TNF $\alpha$ therapy during a one-year follow-up. The two subgroups show a differential enrichment of mucosa associated microbiota genera with prevalence of Prevotella in patients with high IL-13mRNA tissue content and Sutterella and Acidaminococcus in patients with low IL-13mRNA tissue content. Conclusion. Assessment of mucosal IL-13mRNA might help in the identification of the patients' subgroup that might benefit from a therapeutic approach modulating IL-13.

Keywords: Ulcerative colitis, IL-13, microbiota 


\section{INTRODUCTION}

A personalized approach to therapy has great promise to improve disease outcomes. Selection of patients as candidates for the early introduction of highly effective therapy can both maximize treatment efficiency and prevent long-term complications. The classic pro-inflammatory cytokines (such as IL-6 and TNF- $\alpha$ ) have an accepted role in the pathogenesis of inflammatory lesions, and recent findings showed that Th17 response also participates in the inflammatory process $(1,2)$. Ulcerative Colitis (UC) has been associated with an atypical Th2 cell response mediated inflammation (3-6). Although some evidences provided a proof of concept that IL-13 is an effector cytokine in UC ${ }^{(7)}$, administration of anti-human IL-13 neutralizing monoclonal antibody, did not significantly improve clinical response vs placebo in UC patients ${ }^{(8)}$. However, in the same study, the proportion of patients who achieved clinical remission was statistically significantly higher in the anti-IL-13 treated group compared with the placebo group ${ }^{(8)}$, suggesting the presence of a UC patients' subgroup responding to IL-13 neutralizing treatment.

It is increasingly evident that there is a close relationship between the microbiota composition and gut immune response, which includes both the cellular and the soluble component of the immune response. Specific components of the gut microbiota are involved in the production of pro-inflammatory cytokines and subsequent generation of Th17 cells ${ }^{(9,10)}$. Similarly, commensal bacteria and their

metabolites can also promote the generation of regulatory $\mathrm{T}$ cells ${ }^{(10-13)}$ which, in turn, influence the microbiota composition ${ }^{(14)}$.

We hypothesize that UC patients might be stratified according to distinctive cytokine profiles and/or to a specific mucosa-associated microbiota. Therefore, we analyzed the mucosal cytokine mRNA content and the mucosa-associated microbiota composition of a cohort of clinically and endoscopic active UC 
patients. We demonstrate, by means of data-driven approach, in the context of a generalized increased mRNA IL-17A tissue content in UC patients, the existence of a specific UC patient subgroup characterized by elevated IL-13 mRNA tissue levels distinct by patients with IL-13 mRNA levels not distinguishable by control subjects. Furthermore, the two patients' subgroups (high and low IL13mRNA tissue content) show different clinical-pathological characteristics and a differential enrichment of mucosa-associated microbiota genera known to be involved in UC dysbiosis. 


\section{METHODS}

Patients. A total of 88 UC patients attending two clinical tertiary centers (IBD, GE Unit, Sandro Pertini Hospital, Rome, and Department of General Surgery, "P. Stefanini", Sapienza University, Rome) with endoscopically active disease (Mayo score $\geq 1{ }^{(15)}$ ) were evaluated. All the patients were not on rectal 5-ASA and/or steroids in the last 3 months, nor had assumed antibiotics in the last 3 months. A control group of 24 subjects undergoing colonoscopy for colon cancer screening or suspected functional bowel disorders was also included. In UC patients, disease extension, at the time of endoscopy, was classified using the Montreal classification ${ }^{(16)}$ as follows: proctitis, involvement limited to the rectum; left-sided colitis, involvement limited to a portion of the colorectum distal to the splenic flexure; extensive colitis, involvement extending proximal to the splenic flexure. Multiple endoscopic mucosal biopsies were obtained from endoscopically involved and uninvolved areas in UC patients, and from matched areas in controls. Histopathology was quantified in H\&E stained tissue sections using the Robarts histopathology index $(\mathrm{RHI}){ }^{(17)}$. $\mathrm{RHI}$ values $<3$ and $>6$ were recorded for all biopsy samples collected from uninyolved and involved tissue, respectively. Histology confirmed the absence of inflammatory changes in controls. For cytokine/microbiota analysis, multiple biopsies taken from involved and uninvolved tissue were stored in RNA later for quantification of cytokine profile and identification of mucosa-associated microbiota by metagenomics analysis. Biopsies samples for RNA extraction were available in $81 \mathrm{UC}$ patients and 21 Controls. 20 controls and 77 patients (77 samples from involved tissue and 50 samples from uninvolved tissue within the same patients) gave rise to a good quality RNA to be amplified. Biopsies for microbiota analysis were available in 24 controls and 88 UC patients. 21 controls and 79 patients (79 samples from involved tissue and 57 samples from uninvolved tissue within the same patients) endowed with a sufficient quality data for sequencing analysis. In 68 patients both RNA and microbiota analysis were available. 
Clinical-pathological variables of patients contributing cytokine, microbiota or cytokine+ microbiota data were largely superimposable. Given the main focus of the study is on the immunological subtyping we report the clinical-pathological variables for the 77 patients data set (Table1).

\section{Cytokine tissue mRNA content quantification}

RNA was extracted using RNA mini Kit Plus (Qiagen, Hilden, Germany) and its quality analyzed by Agilent RNA 6000 Nano Kit using Agilent 2100 Bioanalyzer instrument (Agilent Technologies, Santa Clara, CA). RNA with Refractive Index Detector (RID) $\geq 7$ was used for subsequent analysis. cDNA was reverse transcribed from $1 \mu \mathrm{g}$ of RNA using the High-Capacity cDNA Reverse Transcription Kit (Applied Biosystems $^{\mathrm{TM}}$ - Thermo Fisher Scientific, Massachusetts, USA). We quantified by quantitative real-time PCR (RTqPCR) the tissue content of TNF- $\alpha$, IL-6, IFN- $\gamma$, IL-17A, IL-10 and IL13 using the following primers: TNF- $\alpha$ forward 5-CCCAGGGACCTCTCTCTAATCA, reverse 5GCTACAGGCTTGTCACTCGG-3; IL-6 forward 5'-CCACTCACCTCTTCAGAACG-3', reverse 5'GCCTCTTTGCTGCTTTCACAC-3'; IFN- $\gamma$ - forward: 5'-ATAGGTAACTGACTTGAATGTCCA-3', reverse 5'-GCTCTTCGACCTCGAAACAGC-3'; IL-17A - forward: 5'ACTACAACCGATCCACCTCAC-3', reverse 5'-ACTTTGCCTCCCAGATCACAG-3'; IL-10forward 5'-CCCAAGCTGAGAACCAAGACC-3', reverse 5'-TCACAGGGAAGAAATCGATGAC3'; IL-13 - commercially available primers RT2 qPCR Primers Assay (Qiagen) cat.PPH00688FRPS. As housekeeping gene, we utilized RPS9 -forward: 5'-AAGCTGATCGGCGAGTATG-3', reverse 5'-

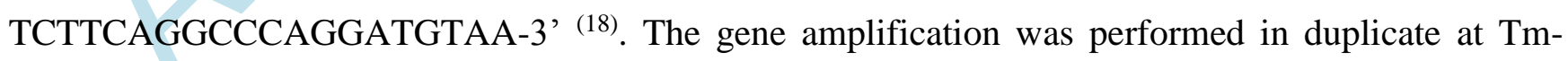
$60^{\circ} \mathrm{C}$ using Fast SYBR ${ }^{\mathrm{TM}}$ Green Master Mix (Applied Biosystems ${ }^{\mathrm{TM}}$ - Thermo Fisher Scientific). Data are expressed as Log2 (Relative Expression) coming from the equation: Relative Expression $=40-\mathrm{DCt}$ where 40 is the maximum number of cycles and DCt is the difference in number of cycles of the gene of interest with the housekeeping gene. We attributed a relative expression of 40 to samples with 
undetectable expression, (threshold cycle $\geq 40$ ); next, we estimated the relative expression as described above.

\section{Statistical analysis}

The presence of a statistically significant difference between controls and UC patients' cytokine tissue mRNA content was assessed by Mann-Whitney's U. The optimal 'clustering properties' of IL-17A and IL-13 with respect to the other cytokines were assessed by means of pseudo F statistics $(19,20)$ bimodality index as well as by the correlation structure among a set of cytokines by means of Pearson correlation and Principal Component Analysis (PCA). The bi-dimensional space spanned by IL-17A and IL-13 was analyzed by K-means ${ }^{(21)}$, the by far most common unsupervised non-hierarchical clustering technique maximizing the Between/Within cluster variance ratio. The choice of the number of clusters (K value) was based upon the maximal distance of the observed R-square (Between cluster variance/Total variance ratio) with the one expected by a Gaussian distribution of data. The search for relevant correlations between cluster composition and clinical-pathological variables was performed by means of Chi-Square statistics and Analysis of Variance for categorical and interval variables respectively.

\section{Mucosal samples collection and bacterial genomic DNA extraction}

Endoscopic biopsies were collected in RNAlater and stored at $-80^{\circ} \mathrm{C}$ until extraction of nucleic acids. The bacterial genomic DNA extraction was carried out with DNeasy PowerLyzer PowerSoilKit (Qiagen, Hilden, Germany) following the manufacturer's instructions. DNA quality was assessed by gel electrophoresis and spectrophotometry, measuring OD 260/280.

\section{S Ribosomal RNA Gene Amplicons preparation and Illumina MiSeq sequencing}

Library of $16 \mathrm{~S}$ rRNA gene amplicons was prepared by IGA Technology Services (Udine, Italy) through amplification of the V3-V4 hypervariable region by using specific-barcoded primers with 
overhang adapters. The standard protocol was followed according to the $16 \mathrm{~S}$ metagenomic sequencing library preparation guide from Illumina (Part \# 15044223 Rev. B; https://support.illumina.com/). Pooled V3-V4 amplicon libraries were sequenced using the Illumina MiSeq platform. Each sample was sequenced at IGA Technology (Udine, Italy) using Illumina MiSeq instrument and a 300-bp paired-end reads protocol.

\section{Sequencing Data analysis}

Demultiplexed reads were downloaded and quality checked using FastQC 0.11.5. Reads were further pre-processed by removing Illumina sequencing adaptors with CUTADAPT ${ }^{(22)}$, and by trimming the low quality end of each read with SICKLE ${ }^{(23)}$, with a quality threshold of 20 . Trimmed forward and reverse reads were then joined with PEAR ${ }^{(24)}$ and checked for chimera presence with VSEARCH ${ }^{(25)}$. OTUs picking was performed in QIIME $1.8^{(26)}$ with uclust algorithm ${ }^{(27)}$ using default values, and assigning the taxonomy using the GreenGenes 13.8 database. Low coverage OTUs were filtered using filter_otus_from_otu_table.py and parameter --min_count_fraction 0.00005 .

Subsequent analyses were performed in R statistical software. The file produced by QIIME was parsed in $\mathrm{R}$ with phyloseq package ${ }^{(28)}$ and OTUs count data were normalized by cumulative sum scaling (CSS) as implemented in the metagenomeSeq package ${ }^{(29)}$. Alpha diversity was evaluated using Observed richness (the number of different OTUs in a sample), Shannon's diversity Index (a measure of community diversity, accounting for both abundance and evenness of bacterial OTUs), and Evenness index (a measure of uniformity of relative abundances of the OTUs in a sample) ${ }^{(30)}$. Beta diversity was analyzed by means of principal coordinate analysis (PCoA) based on Bray-Curtis dissimilarity index producing an explicit metric space from microbiome profiles dissimilarities. Inferential statistics on the above described metrics was performed by Analysis of Variance and Student's t-test. LEfSe (Linear discriminant analysis Effect Size) ${ }^{(31)}$ on the CSS transformed abundances, was performed to identify plausible bacterial biomarker(s) able to separate different 
groups. In LEfSe, Kruskal-Wallis rank-sum test (significance threshold 0.05) was firstly used to identify significantly different taxa abundances among classes (in this case, we used patients' clusters as group variable), and then LDA (linear discriminant analysis) is used to estimate the size of the discriminating effect for each feature. A feature (i.e. a Genus-level OTU) is retained as a suitable biomarker of a class if the LDA value (Between/Within Variance ratio) was higher than 2.

Microbiota sequence data are available at http://www.ebi.ac.uk, under the accession number

PRJEB31884. The script used for pre-treatment and OTUs picking, as well as the script for data analysis performed in $\mathrm{R}$, are available at the following GitHub repository https://github.com/FrancescoVit/Supplementary-to-Butera-et-al.-2019 


\section{RESULTS}

\section{IL-13 mRNA tissue content allows for a meaningful classification of UC patients}

We preliminary analyzed the mRNA tissue content of different cytokines in UC patients and control subjects. As illustrated in Figure 1, in UC patients, all the cytokines evaluated show significantly increased mRNA tissue content in the involved tissue vs uninvolved tissue that in turn show values comparable to controls. However, it is worth noting IL-13 values have a clear bimodal distribution, while IL-17A values in UC involved tissue show the smallest overlap with the controls suggesting discriminatory ability in separating the two groups. Analysis of Variance as applied to controls-patients discrimination resulted statistically significant for all the analyzed cytokines with the only exception of IL-13 (Supplementary Table 1). Moreover, IL-13 distribution and the related quantile-quantile (Q-Q) distribution (Supplementary Figure 1, panel A and B, respectively) clearly show a deviation from the normal distribution for both patients and controls, thus not related to "a priori class discrimination" suggesting clustering relevance of IL-13 for the detection of disease sub-groups. This suggestion had a strong proof by the application of two independent computational approaches: a) Bimodality estimation by Pseudo F statistics ${ }^{(19,20)}$ and b) Pearson correlation and Principal Component Analysis as applied to cytokine profile of UC patients.

Pseudo-F statistics corresponds to the ratio of Between/Within cluster variance: the greater this ratio, the greater the relevance of the clusters. In the case of two clusters, the Pseudo-F is an index of bimodality, with high values pointing to the presence of two distinct populations in the same set.

We computed the Pseudo-F statistics on the two cluster optimal K-means solution for all the evaluated cytokines independently from the control/patient a priori classification. According with this analysis IL-17A and IL-13 were the two cytokines endowed with the higher values of the index and thus the two optimal variables for classification purposes (Supplementary Table 2). In the case of IL-17A, Pseudo-F 
registers the control/patient discriminatory power of this cytokine. On the contrary, the lack of any control/patient discriminant power of IL-13 makes the elevated Pseudo-F values of this cytokine the image in light of a different latent biological categorization.

Even more compelling, we found that the differences in mRNA tissue content of the involved vs uninvolved colonic area from the same patient relative to IL-6, TNF- $\alpha$, IFN- $\gamma$ and IL-10 were each other strongly correlated (Pearson correlation coefficient), while IL-17A and IL-13 variations were both independent from all the other cytokine mRNA concentration and independent of each other. This correlation structure gave rise to a three principal components (PCs) solution of the entire cytokine space (Supplementary Table 3). The first principal component (PC1, explaining 49\% of total variance) consists in an aspecific inflammatory response including the joint variation of all the cytokines evaluated, with the exception of IL-13 and IL-17A. Notably, IL-13 and IL-17A belong to two mutually independent components (PC2 and PC3) explaining 19.4\% and 16.5\% of total variance respectively. The inspection of component loading, correspondent to the Pearson correlation between original variable and components (Supplementary Table 3 and accompanying Figure) identifies PC2 with IL-13 (Pearson $\mathrm{r}=0.94$ ) and PC3 with IL-17A (Pearson $\mathrm{r}=0.96$ ) respectively. The above results point to additional properties (the components are each other orthogonal by construction) of IL-13 and IL-17A (PC2 and PC3), independent from aspecific inflammation (PC1) that can be used to identify subgroups of UC patients by means of a clustering approach on these two cytokines. Thus, while PC1 is a 'size' component (32, 33), both $\mathrm{PC} 2$ and $\mathrm{PC} 3$ are 'shape' components independent of the 'entity' of inflammation (registered by PC1) and potentially useful for the discrimination of disease sub-groups. 


\section{UC patients are distributed in clusters characterized by high and low IL-13 mRNA}

Given the above described observations, we concentrated on IL-13 and IL-17A mRNA levels in order to single out a reliable partition of the data. As shown in Figure 2, the combination of the two cytokines indeed clearly separated UC patients from control subjects confirming the significant alteration of the two cytokine expression due to the disease. We then evaluated the distribution of subjects in the IL17A/IL-13 plane. As shown in Figure 3A only UC patients have IL-17A values greater than the mean value of IL-17A (right quadrants), while, as far as IL-13 values, the higher than mean values belong to both UC patients and control subjects although the former are prevalent. Thus, distribution of IL-17A and IL-13mRNA values points to the existence of discrete clusters of subjects. A k-means cluster analysis on the IL-17A/IL-13 plane was computed (Figure 3B). It is worth to stress that k-means is an unsupervised technique and does not take into account the class of the subjects (patients or controls) but only their mutual relations in the IL-17A/IL-13 plane. Data represented in Supplementary Figure 2 points to a six clusters partition as optimal. The six clusters partition explains $91 \%$ of the total information present in the data set (R-square=0.91). With the only exception of cluster 1 (accommodating for two outlier observations), the classes are sufficiently populated to allow for a reliable profiling of IL-17A and IL-13 tissue content. The IL-17A mRNA tissue content varies smoothly from healthy to diseased patients: the 'extreme' cluster 6 and cluster 2 are devoid of any control subject, while the intermediate and 'left side of the plane' clusters have a mixed controls/UC populations (Figure 3B). Cluster 6 is made of patients with 'high IL-17A/high IL-13' pattern, while cluster 2 have a 'high IL-17A/low IL-13' pattern (Figure 3B). The above analysis allows us to define a bipartite profile of UC patients according to 'high IL-13' (Cluster 6) and 'low IL-13' (Cluster 2) mRNA tissue content in the context of high IL-17A mRNA tissue content. 
Clusters in the IL-13/IL-17A plane show differences as for sex, age at diagnosis, prevalence of extensive colitis and steroid/immunosuppressant/anti-TNF-a therapy use

Having proved the existence of patient cluster distribution (further confirmed by bootstrap simulations), we analyzed the observed cytokine-based patient subgroups according to the clinicalpathological variables. We preliminary assessed the presence of differences in the clinical--pathological variable among the clusters 2, 3 and 4 (low IL-13mRNA content) and between the clusters 5 and 6 (high IL-13 mRNA content). Since we did not find any statistical differences (Supplementary Table 4) we grouped cluster 2, 3 and 4 (low IL-13mRNA content) and cluster 5 and 6 (high IL-13mRNA content) for the analysis. No differential distribution as for disease duration (139 \pm 20 vs $123 \pm 16$ months, mean $\pm \mathrm{SE}$; $\mathrm{p}=0.5$, low and high IL-13 subset, respectively), therapy at time of endoscopy (corticosteroids, immunosuppressant, biological therapy at the time of endoscopy: $33 \%$ vs $32 \%$ low

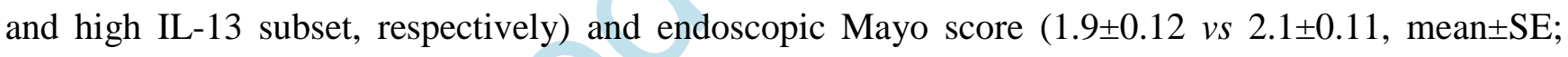
$\mathrm{p}=0.38$, low and high IL-13 subset, respectively), was observed. A significantly lower prevalence of females was observed in patients belonging to low IL-13 mRNA tissue content (Figure 4A). Patients with high IL-13 mRNA tissue content show a significant lower age at diagnosis than patients with low IL-13 mRNA tissue content (Figure 4B). A significant higher prevalence of patients with extensive colitis was observed in patients with high IL-13 mRNA than in patients with low IL-13 mRNA tissue content (Figure 4C). In 42 out of the 77 patients, information regarding therapy during at least 1 year of follow-up was available. This subset of patients did not differ from the whole group as for clinical-pathological variables at entry (Supplementary Table 3). Furthermore, the distribution along different clusters of the 42 patients in which follow up was available did not differ from the whole set distribution (clusters 2+3+4: 41.86\% vs 42.86\%; clusters 5+6: $58.14 \%$ vs $57.14 \%$, respectively). Therefore, we considered the 42 patients subset as an unbiased subsample of the whole set. 
In this subset of patients, the relative frequency of clinical relapses during the one-year follow-up period did not differ between patients with low and high IL-13mRNA content (27 vs $29 \%$, proportion of patients with clinical relapses, respectively). However, patients with high IL-13 mRNA showed, during the follow-up, but not at the time of endoscopy (corticosteroids, immunosuppressant, biological therapy: $27.78 \%$ vs $20.83 \%$ low and high IL-13 subset, respectively), increased steroid/ immunosuppressant/anti-TNF- $\alpha$ therapy use to reach and maintain the remission, when compared with patients with low IL-13mRNA (Figure 4D). Taken together, the above results suggest that UC patients showing high IL-13 mRNA tissue content have a more severe colitis than patients showing low IL-13 mRNA tissue content.

When males and females were separately analyzed for the clinical-pathological variables described above, it appears that the only variable influenced by gender was the age at diagnosis where males contributed to the observed significant lower age at diagnosis in patients belonging to clusters $5+6$ (males clusters 5+6: 30 (4-61) vs males clusters 2+3+4: 42 (20-74), median (range); $\mathrm{p}=0.0043$, by Mann Whitney test).

\section{Characterization of mucosa-associated microbiota in UC patients and controls}

To investigate the ability of microbiota composition to identify different UC patients subsets or to complement cytokine profile information, we preliminary evaluated mucosal microbiota composition in UC patients (both in involved and uninvolved tissue) and in controls, by performing Illumina MiSeq sequencing of $16 \mathrm{~S}$ rDNA. A summary of microbiota profiles (relative abundances) at family level is reported in Figure 5A.

As for $\alpha$-diversity (Supplementary Figure 3) and $\beta$-diversity (Figure 5B), we did not observe major differences in the mucosa-associated microbial profiles between UC and Controls (both involved and uninvolved tissue). Furthermore, we did not observe major differences between involved and 
uninvolved tissue in UC patients. Interestingly, PCoA performed on Bray-Curtis distances suggests a three group's ordination of mucosa-associated microbial profiles, varying independently from mucosal tissue type (involved, uninvolved, control mucosa) (Figure 5B), IL-13 and IL-17 tissue cytokine content (Supplementary Figure 4), cytokine clusters (Supplementary Figure 5), as well as clinicalpathological variables (Supplementary Table 5).

Considering the data-driven characteristic of PCoA, this implies neither disease, nor cytokine profile are relevant order parameters of the microbiota profile. Thus, the global microbiota profile stems from other biological features (e.g. diet, micro-environmental features, genetics) and we can only focus on local microbial features to try to get a 'signature' of the disease and cytokine status. This methodologically implies the shift from a data-driven (PCoA) to a supervised (Discriminant Analysis) approach. When discriminant microbial signatures were investigated by LEfSe analysis (Figure 5C-D), comparison between controls mucosa-associated microbiota (Controls, gray highlighted node of the tree) and UC mucosa-associated microbiota (both involved and uninvolved, red node of the tree) showed an enrichment of Roseburia genus in control mucosa compared to UC (Figure 5C), as previously reported in several studies ${ }^{(34-36)}$.

UC samples (involved and uninvolved tissue) showed relative enrichment of Bifidobacteriaceae, Gemellaceae, Enterococcaceae, Eryspelothricaceae, and Lactobacillales, including also Bifidobacterium, Enterococcus and Acidaminococcus genera (Figure 5B). When we examined differential taxa between involved mucosa and uninvolved mucosa (Figure 5C), Bifidobacterium and Acidaminococcus genera and Gemellaceae family were enriched in uninvolved mucosa, while, Lactobacillus, Eubacterium and Enterococcus genera were enriched in the involved mucosa. These data are in agreement with the reported increase in UC fecal samples of Enterococcaceae, Lactobacillaceae ${ }^{(37)}$ families and Enterococcus genus ${ }^{(38)}$ suggesting that the contribution to the reported increase in fecal samples is mainly due to the increase observed in inflamed tissue. 
Mucosal microbiota composition was further analyzed focusing on the subset of involved tissues in subjects belonging to cytokine Cluster 6 (CL) and CL 2, the two clusters populated by UC patients only characterized by high and low IL-13 mRNA, respectively. Alpha diversity analysis (i.e. richness, evenness, Shannon's index, and Faith's phylogenetic diversity index; Supplementary Figure 6A) and beta diversity (Supplementary Figure 6B) did not highlight differences between involved mucosaassociated microbiota of patients in CL6 and CL2. Interestingly, when we selected only samples belonging to CL6 and CL2 to evaluate their B-diversity (Supplementary Figure 6B), the spatial arrangement of samples on the ordination space (PCoA based on Bray-Curtis distances) resembled the one observed in the complete samples population (Figure 5B). This evidence further confirms our previous observation that the global microbiota profile stems from other biological features than cytokine status alone.

Nevertheless, when differences between involved mucosa-associated microbiota of patients belonging to the two cluster that show the lowest (CL2) and the highest (CL6) IL-13 values were evaluated by LEfSe (Figure 6), Prevotella genus resulted a microbial signature associated to subjects in CL6, while Acidaminococcus and Sutterella genera, were associated to patients in CL2.

Interestingly, a more in-depth sequencing analysis at species-level revealed that $2.5 \%$ of the total number of the reads $\left(218^{\prime} 557\right.$ out of $8^{\prime} 498^{\prime} 053$ total number) were assigned to Prevotella spp. and Prevotella copri was present in more than 50\% of the CL6 samples (Supplementary Figure 7). 


\section{DISCUSSION}

In the present study, we demonstrated the existence of two different subsets of adult endoscopically active UC patients characterized, in the context of a generalized increase of IL-17A tissue mRNA content, by high and low IL-13 tissue mRNA content. Patients in the two subsets show different clinical-pathological characteristics and some local microbial markers.

Among the cytokines explored in the present study, only IL-17A and IL-13 show classificatory ability independent from the global inflammatory status of the patients (PC1, see Results). IL-17A and IL-13 are each other linearly independent, with IL-17A marking the 'presence of disease' and IL-13 the disease sub-typing. Our observation of increased IL-17A expression in UC is in line with previous observations by our and other groups ${ }^{(2,7,39,40)}$, and with a recent report in which a large cohort of pediatric patients was evaluated ${ }^{(41)}$. Notably, in the last reported study, increased IL-17A and IL-13 mRNA tissue content (with no significant correlation between IL-13 and IL-17A expression) were increased in ulcerative colitis and IL-17A and IL-5 mRNA expression were able to distinguish UC from colon-only Crohn's disease ${ }^{(41)}$. It has been recently shown that the ratio of mucosal IL17A to IL17F expression correlate significantly with endoscopic disease activity in adult UC ${ }^{(42)}$ and we previously demonstrated that dual expression of IL17A by CD4+CD25- regulatory T cells expressing surface transforming growth factor- $\beta$ in its latent form (LAP) reduces the suppressor activity of these cells in UC ${ }^{(2)}$. In addition to IL-17A, sufficient evidence points to IL-13 as an important pathological factor in adult and pediatric UC patients ${ }^{(3,4,41,43,44)}$, although few reports ${ }^{(45,46)}$ did not show increased level of IL-13 in UC patients. The reason for such discrepancies may reside in both the different experimental techniques ${ }^{(45,46)}$ and the very low number of patients in which IL-13mRNA was evaluated ${ }^{(45)}$ in the latter mentioned studies. 
The two subsets of UC patients observed in the present study differ in the prevalence of gender, being females more represented in the high IL-13 subset, as well as in the age at diagnosis that was significantly lower in the high IL-13 patients' subset when compared to the low IL-13 patients' subset. No significant difference between the two subsets in the disease duration from the diagnosis was observed.

As regard disease characteristics, the high IL-13 patients' subset show an increased prevalence of extensive colitis. Furthermore, in the group of 42 patients in which clinical information during the follow-up were available, the use of steroids, immunosuppressant and biological agents to achieve and maintain clinical remission, not significantly different at the time of endoscopy, was higher in the high IL-13 patients' subset than in the low IL-13 patient's subset. Taken together data suggest that UC patients showing high IL-13 mRNA tissue content have a more severe colitis than patients with low IL13 mRNA tissue content. This finding somehow differs from the observation reported in a treatmentnaive UC pediatric patients cohort characterized by concomitant increased mucosal IL-17A and IL-13 mRNA ${ }^{(41)}$. In this cohort of patients, higher IL-13 expression was associated significantly with an increased likelihood of clinical response at 6 and 12 months to first-line therapies (i.e. corticosteroids, mesalamine, and thiopurines) and steroid free remission compared with that of patients characterized by essentially undetectable IL-13 expression. Moreover, during the same period of time, these patients were less exposed to anti-TNF-biologic drugs. In our cohort, patients with high and low IL-13 mRNA did not differ in the clinical response or in the percentage of patients experiencing a clinical relapse during the one year follow-up, however the use of systemic corticosteroids, immunosuppressant and anti-TNF- $\alpha$ biologic drugs was higher in the high IL-13 mRNA patient subset. It is quite possible that in newly diagnosed pediatric patients in which the immune-response is not influenced by the effects of inflammatory relapses and consequent therapy, initial induction of IL-13 is adequately counteracted by the standard therapy. Alternatively, increased production of IL-13 might even have, in the initial phase 
of the disease, a protective role, as shown in some animal models ${ }^{(47-49)}$. However, with the progression of the disease, inflammatory flares and their treatment might induce changes favoring the occurrence or amplification, in genetically predisposed individuals, of autoimmunity phenomena as trigger of IL-13 production that switch the role of IL-13 production from protective to pathogenic. Indeed, in adult UC patients, it has been recently demonstrated the presence in colonic lamina propria of increased proportion of NKT cells able to produce IL-13 in response to lysosulfatide, a sulfatide glycolipid ${ }^{(50)}$. Sulfatide glycolipids are self-antigens present in cells in many tissues including the epithelial cells in the gastrointestinal tract. A stress response of genetically conditioned epithelial cells to certain type of bacteria in the colonic microbiota may indeed promote the autoimmune-induced IL-13 production. Interesting, in the present study, we observed different mucosal microbial profiles associated to the two patients' subsets. Particularly, while mucosa-associated microbiota in patients with high IL-17A and low IL-13mRNA is enriched in Sutterella and Acidaminococcus, Prevotella (mainly Prevotella copri) is enriched in the mucosa-microbiota of patients showing increased IL-13 mRNA content in addition to high IL-17A mRNA content. It is worth to note that Sutterella ${ }^{(51)}$, Acidaminococcus ${ }^{(52)}$ and Prevotella copri ${ }^{(53)}$ have been reported to be increased in fecal microbiota of UC patients. All of these microorganisms are classically considered commensal bacteria due to their extensive presence in the healthy human body. However, emerging studies have linked increased Prevotella abundance and specific strains to inflammatory disorders, suggesting that at least some strains exhibit pathobiontic properties. In particular, it has been recently reported that expansion of Prevotella copri in fecal samples strongly correlate with disease in new-onset untreated patients with rheumatoid arthritis, a systemic autoimmune disease ${ }^{(54)}$. In the same study it has been described its ability, after colonization of mice, to increase sensitivity to chemically induced colitis ${ }^{(54)}$. Indeed Prevotella might disrupt the mucosal barrier function through production of sulfatases that actively degrade mucus oligosaccharides (55). Thus, it is plausible that the dysbiotic community observed in the high IL-13 mRNA patients 
subsets (enriched in Prevotella genus), might influence the epithelial stress response, favoring the presentation of autoantigens contributing to the pathogenic role of IL-13. On the other hand, the microbial community enriched in both Sutterella and Acidaminococcus, characterizing the low IL-13 mRNA subset of patients, might contribute to a less severe disease. In fact, although Sutterella was described to be associated with lack of remission after fecal microbiota transplantation ${ }^{(56)}$, recent studies, showed the ability of Acidaminococcus genus to produce short chain fatty acids ${ }^{(57)}$. Short chain fatty acids are in fact considered important metabolites as they serve as the major energy source for colonocytes, they have anti-inflammatory properties and regulate gene expression, in host cells ${ }^{(58)}$. The existence of the two subsets of patients observed in the present study introduces some issues about the clinical implications of the finding. It is presently unknown whether the two subsets of patients are such since the onset of the disease or if they represent different stages of the disease. Very recently, it has been reported, in 15 patients with active ulcerative, that mucosal immune profiles differ during early and late phases of the disease, with a Th1 and Th2-driven prevalent profile disease in early and late disease, respectively ${ }^{(59)}$. However, in the study, IL-13 expression in paired samples from early and late disease has not been evaluated. Patients evaluated in the present study have, at the time of endoscopy, a median time of 9 years of disease duration from the diagnosis thus belonging, according to the above-reported study, to the "late disease". However, we did not observe differences in the disease duration between the two patients' subsets, yet the age at diagnosis was significantly lower in patients with high IL-13 and these same patients showed more frequently an extended colitis, similar to the observations reported in pediatric patients ${ }^{(41)}$. Therefore, we favor the view about the existence of subsets of UC patients showing different IL-13mRNA content from the onset of the disease.

The different cytokine profile might be differentially associated to the presence of different serological markers and to their prognostic ability ${ }^{(60,61)}$, so that it might be useful to combine the assessment of 
tissue cytokine profile with the assessment of serological markers to obtain an increased prognostic ability.

Finally, the findings described in the present study might have important implications on therapeutic strategies in UC. The observation that IL-6, TNF- $\alpha$, IFN- $\gamma$ and IL-10 mRNA tissue content were each other strongly correlated, while IL-17A and IL-13 variations were both independent from all the other cytokines and independent of each other suggests that IL-17A and IL-13 mRNA contents are distinctive features of the pathogenic process of UC. As that, therapy oriented to the neutralization of inflammatory cytokines might only indirectly and differentially affect the IL-17A and IL-13 expression which in turn might influence the response to the neutralization of inflammatory cytokines. Notably, it has been shown that response to infliximab treatment was significantly associated with higher pretreatment mucosal IL-17A gene expression ${ }^{(62)}$, and fewer Gata3+ T cells were observed in the lamina propria of anti-TNF- $\alpha$ responders, than in non-responders patients ${ }^{(63)}$. Beyond these considerations, an important therapeutic implication of the findings reported in the present study concerns the treatment of patients with high IL-13 mRNA tissue content. As recently highlighted ${ }^{(64,65)}$ previous results obtained with IL-13 neutralizing treatments might be reconsidered according to the IL13mRNA colonic content of the patients that have been studied. A treatment approach that specifically target IL-13 or a different IL-13 receptor ${ }^{(66)}$ might indeed be effective in the patients' subset with high IL-13mRNA tissue content identified in this study. 
Funding: This work was supported by the Italian Ministry of Health, Project Code: [RF-201102350689].

Conflict of interest: the Authors declare no conflict of interest

Ethical approval. All participants provided written informed consent prior to inclusion in the study. Ethical approval was provided by the Ethical Committee of the Istituto Superiore di Sanità (Reference: Pre-C-871/14, 25/11/2014). 
Authors' contributions: Study conception and design: MB and AP. Study supervision: MB. Acquisition of data: AB, MDP, FV. Statistical analysis AG, FV. Patients' enrollment, endoscopy, and biopsies collection: AP and RP. Clinical data collection: DD and FC. Histology and histological score: FB. Analysis and interpretation of data: AB, AG, RP, AP, MDP, FV, CDF, DC and MB. Drafting of manuscript: AB, MDP, FV, AG, and MB. Critical revision: AP, RP, AG, CDF, and MB. All the authors have approved the final draft submitted. 
Acknowledgments. The authors wish to thank all patients who donated biological material for the purposes of the study, Doriana Campanile (National Center for Drug Research and Evaluation, Istituto Superiore di Sanità) for technical assistance. 


\section{REFERENCES}

1. Kobayashi T, Okamoto S, Hisamatsu T, Kamada N, Chinen H, Saito R, Kitazume MT, Nakazawa A, Sugita A, Koganei K, Isobe K, Hibi T. IL23 differentially regulates the Th1/Th17 balance in ulcerative colitis and Crohn's disease. Gut. 2008; 57:1682-9

2. D'Ambrosio A, Cossu A, Amendola A, Zandri A, Butera A, Sanchez M, Biffoni M, Pronio A, Montesani C, Kohn A, Pica R, Boirivant M. Lamina Propria CD4+LAP+ Regulatory T Cells Are Increased in Active Ulcerative Colitis but Show Increased IL-17 Expression and Reduced Suppressor Activity. J Crohns Colitis. 2016; 10:346-53.

3. Fuss IJ, Neurath M, Boirivant M, Klein JS, de la Motte C, Strong SA, Fiocchi C, Strober W. Disparate CD4+ lamina propria (LP) lymphokine secretion profiles in inflammatory bowel disease. Crohn's disease LP cells manifest increased secretion of IFN-gamma, whereas ulcerative colitis LP cells manifest increased secretion of IL-5. J Immunol. 1996;157:1261-70.

4. Fuss IJ, Heller F, Boirivant M, Leon F, Yoshida M, Fichtner-Feigl S, Yang Z, Exley M, Kitani A, Blumberg RS, Mannon P, Strober W. Nonclassical CD1d-restricted NK T cells that produce IL-13 characterize an atypical Th2 response in ulcerative colitis. J Clin Invest. 2004; 113:1490-7.

5. Gerlach K, Hwang Y, Nikolaev A, Atreya R, Dornhoff H, Steiner S, Lehr HA, Wirtz S, Vieth M, Waisman A, Rosenbauer F, McKenzie AN, Weigmann B, Neurath MF. TH9 cells that express the transcription factor PU.1 drive T cell-mediated colitis via IL-9 receptor signaling in intestinal epithelial cells. Nat Immunol. 2014; 15:676-86.

6. Nalleweg N, Chiriac MT, Podstawa E, Lehmann C, Rau TT, Atreya R, Krauss E, Hundorfean G, Fichtner-Feigl S, Hartmann A, Becker C, Mudter J. IL-9 and its receptor are predominantly involved in the pathogenesis of UC. Gut. 2015; 64:743-55. 
7. Mannon PJ, Hornung RL, Yang Z, Yi C, Groden C, Friend J, Yao M, Strober W, Fuss IJ. Suppression of inflammation in ulcerative colitis by interferon- $\beta$ - $1 \mathrm{a}$ is accompanied by inhibition of IL-13 production. Gut. 2011; 60:449-55

8. Danese S, Rudziński J, Brandt W, Dupas JL, Peyrin-Biroulet L, Bouhnik Y, Kleczkowski D, Uebel P, Lukas M, Knutsson M, Erlandsson F, Hansen MB, Keshav S. Tralokinumab for moderate-to-severe UC: a randomised, double-blind, placebo-controlled, phase IIa study. Gut. $2015 ; 64: 243-9$.

9. Ivanov II, Atarashi K, Manel N, Brodie EL, Shima T, Karaoz U, Wei D, Goldfarb KC, Santee CA, Lynch SV, Tanoue T, Imaoka A, Itoh K, Takeda K, Umesaki Y, Honda K, Littman DR. Induction of intestinal Th17 cells by segmented filamentous bacteria. Cell. 2009; 139:485-498.

10. Goto Y, Panea C, Nakato G, Cebula A, Lee C, Diez MG, Laufer TM, Ignatowicz L, Ivanov II. Segmented filamentous bacteria antigens presented by intestinal dendritic cells drive mucosal Th17 cell differentiation. Immunity. 2014; 40:594-607.

11. Atarashi K, Tanoue T, Shima T, Imaoka A, Kuwahara T, Momose Y, Cheng G, Yamasaki S, Saito T, Ohba Y, Taniguchi T, Takeda K, Hori S, Ivanov II, Umesaki Y, Itoh K, Honda K. Induction of colonic regulatory T cells by indigenous Clostridium species. Science. 2011; $331: 337-341$.

12. Atarashi K, Tanoue T, Oshima K, Suda W, Nagano Y, Nishikawa H, Fukuda S, Saito T, Narushima S, Hase K, Kim S, Fritz JV, Wilmes P, Ueha S, Matsushima K, Ohno H, Olle B, Sakaguchi S, Taniguchi T, Morita H, Hattori M, Honda K. Treg induction by a rationally selected mixture of Clostridia strains from the human microbiota. Nature. 2013; 500:232-236.

13. Furusawa Y, Obata Y, Fukuda S, Endo TA, Nakato G, Takahashi D, Nakanishi Y, Uetake C4, Kato K, Kato T, Takahashi M, Fukuda NN, Murakami S, Miyauchi E, Hino S, Atarashi K, Onawa S, Fujimura Y, Lockett T, Clarke JM, Topping DL, Tomita M, Hori S, Ohara O, Morita 
T, Koseki H, Kikuchi J, Honda K, Hase K, Ohno H. Commensal microbe-derived butyrate induces the differentiation of colonic regulatory T cells. Nature. 2013; 504:446-450.

14. Josefowicz SZ, Lu LF, Rudensky AY. Regulatory T cells: mechanisms of differentiation and function. Annu. Rev.Immunol. 2012; 30:531-564.

15. Rutgeerts P, Sandborn WJ, Feagan BG, Reinisch W, Olson A, Johanns J, Travers S, Rachmilewitz D, Hanauer SB, Lichtenstein GR, de Villiers WJ, Present D, Sands BE, Colombel JF. Infliximab for induction and maintenance therapy for ulcerative colitis. $N$ Engl $J$ Med. 2005; 353:2462-76.

16. Silverberg MS, Satsangi J, Ahmad T, Arnott ID, Bernstein CN, Brant SR, Caprilli R, Colombel JF, Gasche C, Geboes K, Jewell DP, Karban A, Loftus EV Jr, Peña AS, Riddell RH, Sachar DB, Schreiber S, Steinhart AH, Targan SR, Vermeire S, Warren BF. Toward an integrated clinical, molecular and serological classification of inflammatory bowel disease: Report of a Working Party of the 2005 Montreal World Congress of Gastroenterology. Can J Gastroenterol. 2005; 19 (suppl A) 5-36.

17. Mosli, MH, Feagan BG, Zou G, Sandborn WJ, D'Haens G, Khanna R, Shackelton LM, Walker CW, Nelson S, Vandervoort MK, Frisbie V, Samaan MA, Jairath V, Driman DK, Geboes K, Valasek MA, Pai RK, Lauwers GY, Riddell R, Stitt LW, Levesque BG. Development and validation of a histological index for UC. Gut. 2017; 66:50-58.

18. Bamias G, Goukos D, Laoudi E, Balla IG, Siakavellas SI, Daikos GL, Ladas SD. Comparative study of candidate housekeeping genes for quantification of target gene messenger RNA expression by real-time PCR in patients with inflammatory bowel disease. Inflamm Bowel Dis. 2013; 19:2840-7.

19. Duda RO, Hart PE. Pattern Classification and Scene Analysis. John Wiley \& Sons. 1973 20. Sarle WS. Cubic Clustering Criterion. SAS Institute. 1983 
21. Fraley $\mathrm{C}$ and Raftery AE. How many clusters? Which clustering method? Answers via modelbased cluster analysis. The Computer Journal. 1998; 41, 578-588.

22. Martin M. Cutadapt removes adapter sequences from high-throughput sequencing reads. EMBnet. Journal. 2011; 17, 10-12.

23. Joshi NA, Fass JN. Sickle: A sliding-window, adaptive, quality-based trimming tool for FastQ files (Version 1.33) [Software] 2011 Available at https://github.com/najoshi/sickle

24. Zhang J, Kobert K, Flouri T, Stamatakis A. PEAR: a fast and accurate Illumina Paired-End reAd mergeR. Bioinformatics. 2014; 30:, 614-620

25. Rognes T, Flouri T, Nichols B, Quince C, Mahé F. VSEARCH: a versatile open source tool for metagenomics. PeerJ. 2016; 4:e2584.

26. Caporaso JG, Kuczynski J, Stombaugh J, Bittinger K, Bushman FD, Costello EK, Fierer N, Peña AG, Goodrich JK, Gordon JI, Huttley GA, Kelley ST, Knights D, Koenig JE, Ley RE, Lozupone CA, McDonald D, Muegge BD, Pirrung M, Reeder J, Sevinsky JR, Turnbaugh PJ, Walters WA, Widmann J, Yatsunenko T, Zaneveld J, Knight R. QIIME allows analysis of high-throughput community sequencing data. Nature methods. 2012; 7:335-336.

27. Edgar RC. Search and clustering orders of magnitude faster than BLAST. Bioinformatics. 2010; 26: 2460-2461.

28. McMurdie PJ and Holmes. S. Phyloseq: an R package for reproducible interactive analysis and graphics of microbiome census data. PloS one. 2013; 8:e61217.

29. Paulson JN, Stine OC, Bravo HC, Pop M. Differential abundance analysis for microbial marker-gene surveys. Nat Methods. 2013; 10:1200-2.

30. Leo Lahti, Sudarshan Shetty et al. Tools for microbiome analysis in R. Version 1.5.28. URL: http://microbiome.github.com/microbiome. 2017. 
31. Segata N, Izard J, Waldron L, Gevers D, Miropolsky L, Garrett WS and Huttenhower C. Metagenomic biomarker discovery and explanation. Genome biology. 2011; 12:R60

32. Giuliani, A. The application of principal component analysis to drug discovery and biomedical data. Drug discovery today. 2017; 22, 1069-1076

33. Jolicoeur P, Mosimann JE. Size and shape variation in the painted turtle. A principal component analysis. Growth. 1960; 24, 339-354.

34. Shah R, Cope JL, Nagy-Szakal D, Dowd S, Versalovic J, Hollister EB, Kellermayer R. Composition and function of the pediatric colonic mucosal microbiome in untreated patients with ulcerative colitis. GUT microbes. 2016; 7:384-96.

35. Morgan XC, Tickle TL, Sokol H, Gevers D, Devaney KL, Ward DV, Reyes JA, Shah SA, LeLeiko N, Snapper SB, Bousvaros A, Korzenik J, Sands BE, Xavier RJ, Huttenhower C. Dysfunction of the intestinal microbiome in inflammatory bowel disease and treatment. Genome Biol. 2012; 3:R79.

36. Machiels K, Joossens M, Sabino J, De Preter V, Arijs I, Eeckhaut V, Ballet V, Claes K, Van Immerseel F, Verbeke K, Ferrante M, Verhaegen J, Rutgeerts P, Vermeire S. A decrease of the butyrate-producing species Roseburia hominis and Faecalibacterium prausnitzii defines dysbiosis in patients with ulcerative colitis. Gut. 2014; 63:1275-83.

37. Imhann F, Vich Vila A, Bonder MJ, Fu J, Gevers D, Visschedijk MC, Spekhorst LM, Alberts R, Franke L, van Dullemen HM, Ter Steege RWF, Huttenhower C, Dijkstra G, Xavier RJ, Festen EAM, Wijmenga C, Zhernakova A, Weersma RK. Interplay of host genetics and gut microbiota underlying the onset and clinical presentation of inflammatory bowel disease. Gut. 201867:108-119. 
38. Nemoto H, Ataoka K, Ishikawa H, Ikata K, Arimochi H, Iwasaki T, Ohnishi Y, Kuwahara T, Yasutomo K. Reduced diversity and imbalance of fecal microbiota in patients with ulcerative colitis. Dig Dis Sci. 2012; 57:2955-64.

39. Fujino S, Andoh A, Bamba S, A Ogawa, K Hata, Y Araki, T Bamba, Y Fujiyama. Increased expression of interleukin 17 in inflammatory bowel disease. Gut. 2003; 52: 65-70.

40. Iboshi Y, Nakamura K, Fukaura K, Iwasa T, Ogino H, Sumida Y, Ihara E, Akiho H, Harada N, Nakamuta M. Increased IL-17A/IL-17F expression ratio represents the key mucosal T helper/regulatory cell-related gene signature paralleling disease activity in ulcerative colitis. $J$ Gastroenterol 2017; 52:315-326.

41. Rosen MJ, Karns R, Vallance JE, Bezold R, Waddell A, Collins MH, Haberman Y, Minar P, Baldassano RN, Hyams JS, Baker SS, Kellermayer R, Noe JD, Griffiths AM, Rosh JR, Crandall WV, Heyman MB, Mack DR, Kappelman MD, Markowitz J, Moulton DE, Leleiko NS, Walters TD, Kugathasan S, Wilson KT, Hogan SP, Denson LA. Mucosal Expression of Type 2 and Type 17 Immune Response Genes Distinguishes Ulcerative Colitis From ColonOnly Crohn's Disease in Treatment-Naive Pediatric Patients. Gastroenterology. 2017;152:1345-1357.e7.

42. Iboshi Y, Nakamura K, Fukaura K, et al. Ogino H, Sumida Y, Ihara E, Akiho H, Harada N, Nakamuta M. Increased IL-17A/IL-17F expression ratio represents the key mucosal T helper/regulatory cell-related gene signature paralleling disease activity in ulcerative colitis.J Gastroenterol 2017;52:315-326.

43. Heller F, Florian P, Bojarski C, Richter J, Christ M, Hillenbrand B, Mankertz J, Gitter AH, Bürgel N, Fromm M, Zeitz M, Fuss I, Strober W, Schulzke JD. Interleukin-13 is the key effector Th2 cytokine in ulcerative colitis that affects epithelial tight junctions, apoptosis, and cell restitution. Gastroenterology. 2005; 129:550-564 
44. Inoue S, Matsumoto T, Iida M, Mizuno M, Kuroki F, Hoshika K, Shimizu M. Characterization of cytokine expression in the rectal mucosa of ulcerative colitis: correlation with disease activity. Am J Gastroenterol. 1999; 94:2441-6.

45. Biancheri P, Di Sabatino A, Ammoscato F, Facciotti F, Caprioli F, Curciarello R, Hoque SS, Ghanbari A, Joe-Njoku I, Giuffrida P, Rovedatti L, Geginat J, Corazza GR, MacDonald TT. Absence of a role for interleukin-13 in inflammatory bowel disease. Eur J Immunol. 2014; $44: 370-385$.

46. Kadivar K, Ruchelli ED, Markowitz JE, Defelice ML, Strogatz ML, Kanzaria MM, Reddy KP, Baldassano RN, von Allmen D, Brown KA. Intestinal interleukin-13 in pediatric inflammatory bowel disease patients. Inflamm Bowel Dis. 2004; 10:593-598.

47. Seno H, Miyoshi H, Brown SL, Geske MJ, Colonna M, Stappenbeck TS. Efficient colonic mucosal wound repair requires Trem2 signaling. Proc Natl Acad Sci U S A. 2009; 106:256261.

48. Wilson MS, Ramalingam TR, Rivollier A, Shenderov K, Mentink-Kane MM, Madala SK, Cheever AW, Artis D, Kelsall BL, Wynn TA. Colitis and intestinal inflammation in IL10-/mice results from IL-13Ra2-mediated attenuation of IL-13 activity. Gastroenterology. 2011; 140:254-264.

49. Monticelli LA, Osborne LC, Noti M, Tran SV, Zaiss DM, Artis D. IL-33 promotes an innate immune pathway of intestinal tissue protection dependent on amphiregulin-EGFR interactions. Proc Natl Acad Sci U S A. 2015; 112:10762-10767.

50. Fuss IJ, Joshi B, Yang Z, Degheidy H, Fichtner-Feigl S, de Souza H, Rieder F, Scaldaferri F, Schirbel A, Scarpa M, West G, Yi C, Xu L, Leland P, Yao M, Mannon P, Puri RK, Fiocchi C, Strober W. IL-13Ra2-bearing, type II NKT cells reactive to sulfatide self-antigen populate the mucosa of ulcerative colitis. Gut. 2014; 63:1728-36. 
51. Santoru ML, Piras C, Murgia A, Palmas V, Camboni T, Liggi S, Ibba I, Lai MA, Orrù S, Blois S, Loizedda AL, Griffin JL, Usai P, Caboni P, Atzori L, Manzin A. Cross sectional evaluation of the gut-microbiome metabolome axis in an Italian cohort of IBD patients. Sci Rep. 2017; $7: 9523$.

52. Altomare A, Putignani L, Del Chierico F, Cocca S, Angeletti S, Ciccozzi M, Tripiciano C, Dalla Piccola B, Cicala M, Guarino MPL. Gut mucosal-associated microbiota better discloses Inflammatory Bowel Disease differential patterns than faecal microbiota. Dig Liver Dis. 2018; pii: S1590-8658(18)31260-X.

53. Lucke K, Miehlke S, Jacobs E, Schuppler M. Prevalence of Bacteroides and Prevotella spp. in ulcerative colitis. J Med Microbiol. 2006; 55:617-624

54. Scher JU, Sczesnak A, Longman RS, Segata N, Ubeda C, Bielski C, Rostron T, Cerundolo V, Pamer EG, Abramson SB, Huttenhower C, Littman DR. Expansion of intestinal Prevotella copri correlates with enhanced susceptibility to arthritis. ELife 2013; 2:e01202.

55. Wright DP, Rosendale DI, Robertson AM. Prevotella enzymes involved in mucin oligosaccharide degradation and evidence for a small operon of genes expressed during growth on mucin. FEMS Microbiol Lett. 2000; 190:73-9.

56. Paramsothy S, Nielsen S, Kamm MA, Deshpande NP, Faith JJ, Clemente JC, Paramsothy R, Walsh AJ, van den Bogaerde J, Samuel D, Leong RWL, Connor S, Ng W, Lin E, Borody TJ, Wilkins MR, Colombel JF, Mitchell HM, Kaakoush NO. Specific Bacteria and Metabolites Associated With Response to Fecal Microbiota Transplantation in Patients With Ulcerative Colitis. Gastroenterology. 2019; 156:1440-1454.e2.

57. Vital M., Penton CR, Wang Q, Young VB, Antonopoulos DA, Sogin ML, Morrison HG, Raffals L, Chang EB, Huffnagle GB, Schmidt TM, Cole JR1, Tiedje JM. A gene-targeted 
approach to investigate the intestinal butyrate-producing bacterial community. Microbiome. $2013 ; 1: 8$

58. Koh A, De Vadder F, Kovatcheva-Datchary P, Bäckhed F. From Dietary Fiber to Host Physiology: Short-Chain Fatty Acids as Key Bacterial Metabolites. Cell. 2016; 165:13321345.

59. Mavroudis G, Magnusson MK, Isaksson S, Sundin J, Simrén M, Öhman L, Strid H. Mucosal and systemic immune profiles differ during early and late phase of the disease in patients with active ulcerative colitis. J Crohns Colitis. 2019, Apr 4. pii: jjz072.

60. Kovacs G, Sipeki N, Suga B, Tornai T, Fechner K, Norman GL, Shums Z, Antal-Szalmas P, Papp M. Significance of serological markers in the disease course of ulcerative colitis in a prospective clinical cohort of patients. PLoS One. 2018; 13:e0194166.

61. Hamanaka S, Nakagawa T, Hiwasa T, Ohta Y, Kasamatsu S, Ishigami H, Taida T, Okimoto K, Saito K, Maruoka D, Matsumura T, Takizawa H, Kashiwado K, Kobayashi S, Matsushita K, Matsubara H, Katsuno T, Arai M, Kato N. Investigation of novel biomarkers for predicting the clinical course in patients with ulcerative colitis. J Gastroenterol Hepatol. 2018; 33:19751983.

62. Rismo R, Olsen T, Cui G, Christiansen I, Florholmen J, Goll R. Mucosal cytokine gene expression profiles as biomarkers of response to infliximab in ulcerative colitis. Scand $J$ Gastroenterol. 2012; 47:538-47.

63. Li J, Ueno A, Fort Gasia M, Luider J, Wang T, Hirota C, Jijon HB, Deane M, Tom M, Chan R, Barkema HW, Beck PL, Kaplan GG, Panaccione R, Qian J, Iacucci M, Gui X, Ghosh S. Profiles of lamina propria $\mathrm{T}$ helper cell subsets discriminate between ulcerative colitis and Crohn's disease. Inflamm Bowel Dis. 2016; 22:1779-1792. 
64. Hoving JC Targeting IL-13 as a Host-Directed Therapy Against Ulcerative Colitis.. Front. Cell. Infect. Microbiol. 2018; 8:395.

65. Mao YM, Zhao CN, Leng J, Leng RX, Ye DQ, Zheng SG, Pan HF. Interleukin-13: A promising therapeutic target for autoimmune disease. Cytokine Growth Factor Rev. 2019;45: $9-23$.

66. Hoving JC, Cutler AJ, Leeto M, C Horsnell WG, Dewals,BG, Nieuwenhuizen NE, Brombacher F. Interleukin 13-mediated colitis in the absence of IL-4R $\alpha$ signaling. Gut 2017;66:2037-2039 


\section{FIGURE LEGEND}

Figure 1: Cytokine mRNA tissue content in controls samples $(n=20)$, in the uninvolved tissue $(n=50)$ and involved tissue ( $\mathrm{n}=77$ ) of UC patients. Lines represent median and range. $\mathrm{p}=$ as for Mann-Whitney test.

Figure 2: Mean values location in the bi-dimensional IL-17A vs IL-13 plane is different in UC ( $\mathrm{n}=77)$ and Controls $(\mathrm{n}=20)$. Data in a bivariate mean/SE plane for both IL-13 and IL-17A. Points represents mean \pm SE.

Figure 3: UC patients are distributed in six clusters characterized by high and low IL-13 mRNA and increased IL-17A mRNA tissue content. Panel A: Data distribution of subjects (UC patients and controls) in the IL-17A/IL-13 plane. Each point represent patient or control IL-17A/IL-13 mRNA values. Lines represent mean of IL-17A and IL-13. Panel B: Distribution of clusters in the IL-17A/IL13 plane. Each point represent patient or control IL-17A/IL-13 mRNA values- associated cluster. Panel A and B: UC patients $n=77$; Controls $n=20$

Figure 4: Clusters in the IL-13/IL-17A plane show differences as for sex (A), age at diagnosis (B), prevalence of extensive colitis (C) and steroid/ immunosuppressant/biological therapy use (D). Panel A, B, and C: UC patients n=77. Panel D: UC patients $n=42$.

Figure 5: Explorative analyses and comparison of mucosal associated microbiota composition in UC and control subjects. (A) Barplot shows the composition at the Family level, according with the Phylum of belonging. Family with relative abundance $<1 \%$ were discarded. (B) PCoA ordination based on Bray-Curtis dissimilarities of mucosal samples from UC (involved, $n=79$, and uninvolved, $\mathrm{n}=57$, tissue) and controls $(\mathrm{n}=21)$. PERMANOVA using the Adonis function with 999 permutations 
resulted not significant. (C-D) LEfSe analysis showing significantly biomarker taxa in two different comparisons, based on (C) disease status: UC (both involved and uninvolved tissue, passed as subclasses t LEfSe) compared to control samples, and (D) tissue: controls versus uninvolved versus involved tissue in UC patients. Cladograms show the most discriminative bacterial clades. Coloured regions/branches indicate differences in the bacterial population structure between the different groups. Statistically significant taxa enrichment among groups was obtained with Kruskal-Wallis test among classes $($ Alpha value $=0.05)$. The threshold for the logarithmic LDA score was 2.0.

Figure 6. Comparison of mucosal microbial profiles between UC patients belonging to Cluster 2 (CL2, $\mathrm{n}=10)$ and Cluster 6 (CL6, $\mathrm{n}=30$ ). LEfSe analysis showing significantly enriched biomarker taxa in CL6 vs CL2 comparisons. Cladogram and barplot show the most discriminative bacterial clades. Colored regions/branches indicate differences in the bacterial population structure between the different CL2 and CL6. Statistically significant taxa enrichment among groups was obtained with Kruskal-Wallis test among classes (Alpha value $=0.05$ ). The threshold for the logarithmic LDA score was 2.0. 
Table 1. Clinical-pathological variables of patients at time of endoscopy

\begin{tabular}{|c|c|c|}
\hline & $\begin{array}{l}\text { Ulcerative Colitis } \\
\qquad \begin{array}{c}\text { n. } \\
77\end{array}\end{array}$ & $\begin{array}{l}\text { Controls } \\
\qquad \begin{array}{l}\text { n. } \\
20\end{array}\end{array}$ \\
\hline $\begin{array}{c}\text { Age at the time of endoscopy } \\
\text { years: median (range) }\end{array}$ & $51(19-82)$ & $57(37-86)$ \\
\hline $\begin{array}{c}\text { Gender } \mathbf{M} / \mathbf{F} \\
(\mathrm{n}) /(\mathrm{n})\end{array}$ & $45 / 32$ & $10 / 10$ \\
\hline $\begin{array}{c}\text { Disease Duration from diagnosis } \\
\text { years: median (range) }\end{array}$ & $9(0-36)$ & \\
\hline $\begin{array}{c}\text { Endoscopic Activity } \\
\text { (Mayo Score) } \\
\text { median (range) }\end{array}$ & $2(1-3)$ & \\
\hline Disease Extension & & \\
\hline Proctitis & 29 & \\
\hline Left Sided Colitis & 29 & \\
\hline Extensive Colitis & 19 & \\
\hline $\begin{array}{c}\text { Therapy } \\
\text { CS }\end{array}$ & $2+10^{*}$ & \\
\hline 5-ASA agents & $50+23 *$ & \\
\hline Immune modulators & $1+10^{*}$ & \\
\hline Biological Agents & $2 *$ & \\
\hline No therapy & 4 & \\
\hline \multicolumn{3}{|l|}{ *Patients with combined therapy } \\
\hline
\end{tabular}


Figure 1

TNF- $\alpha$

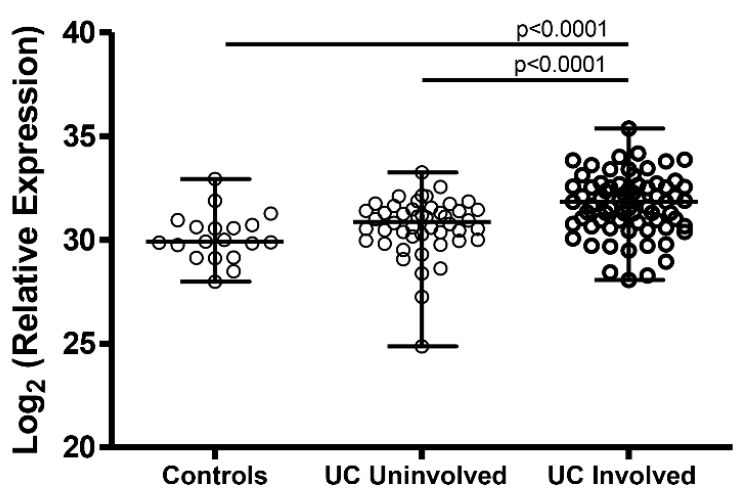

IFN- $\gamma$

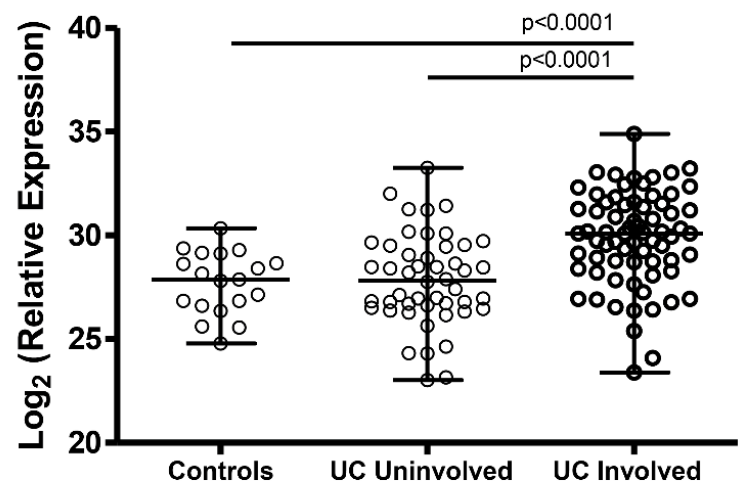

IL-17A

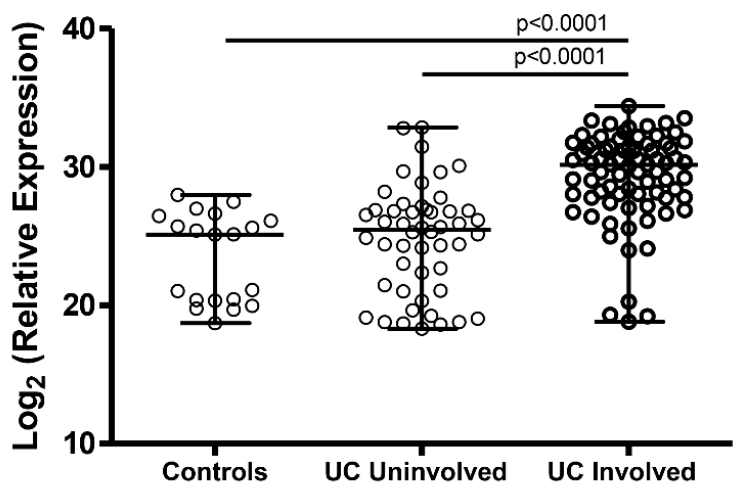

IL-6

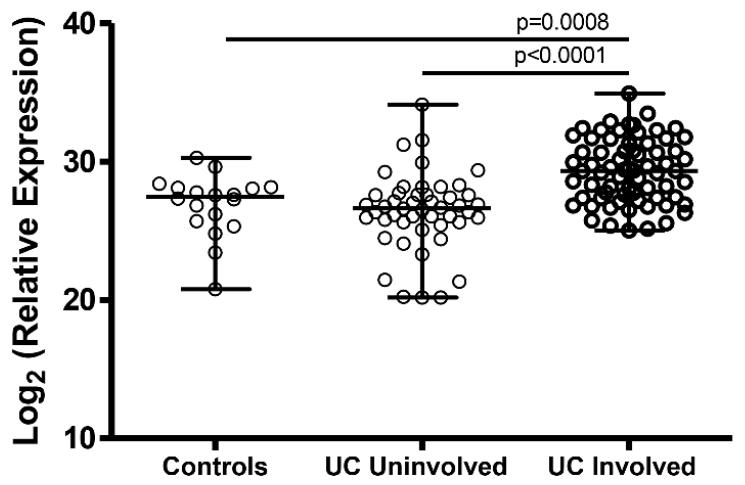

IL-10

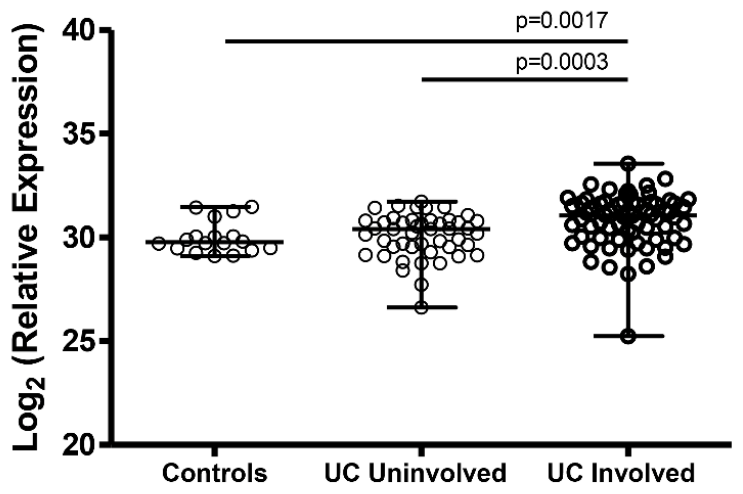

IL-13

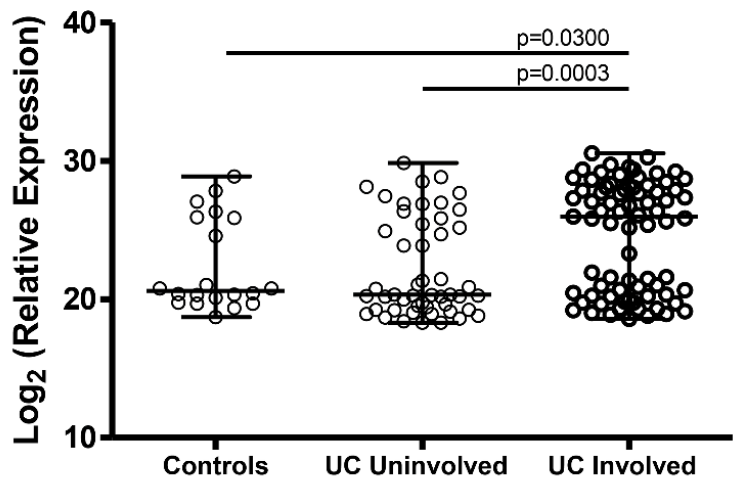


Figure 2

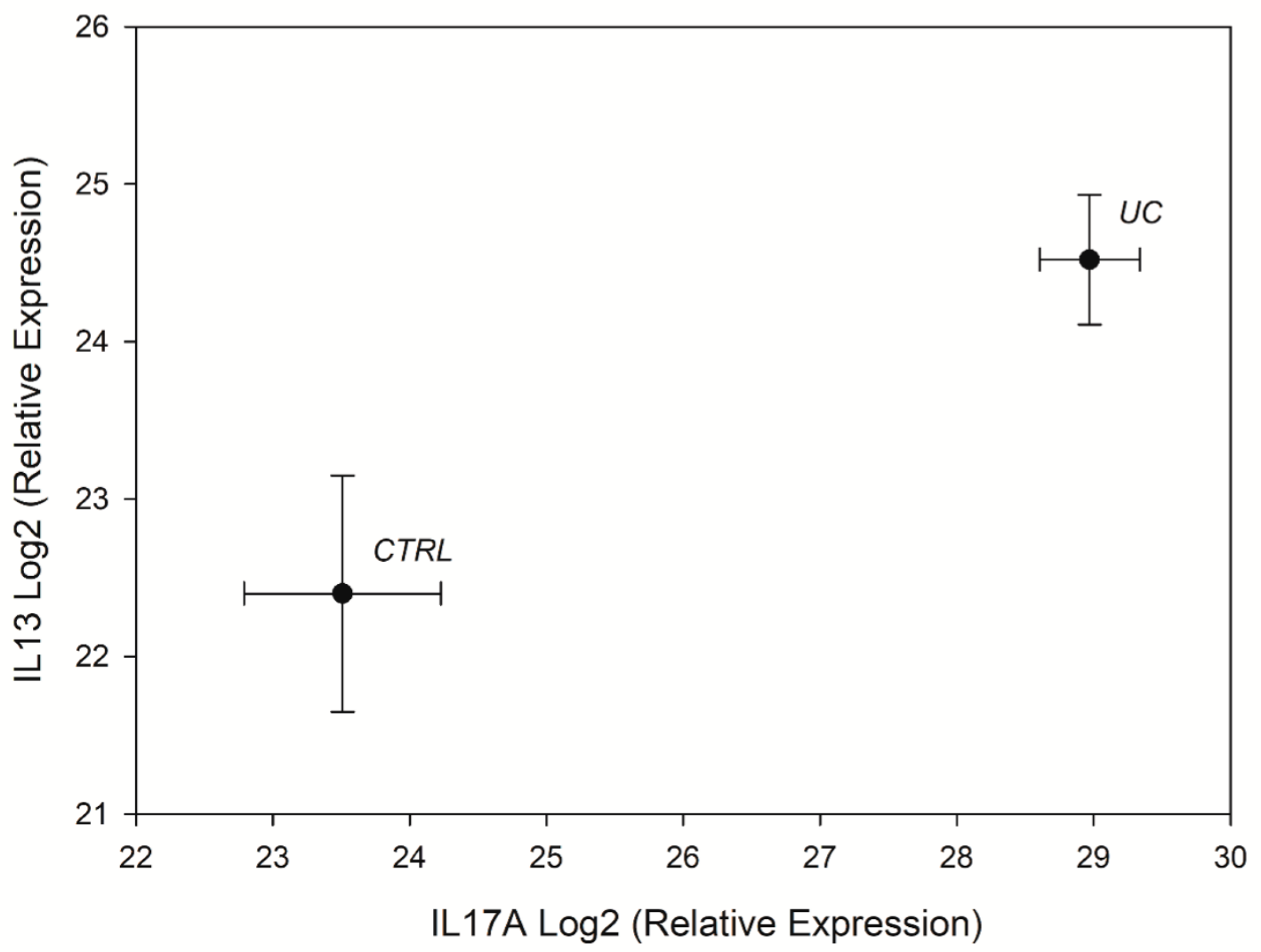


Figure 3
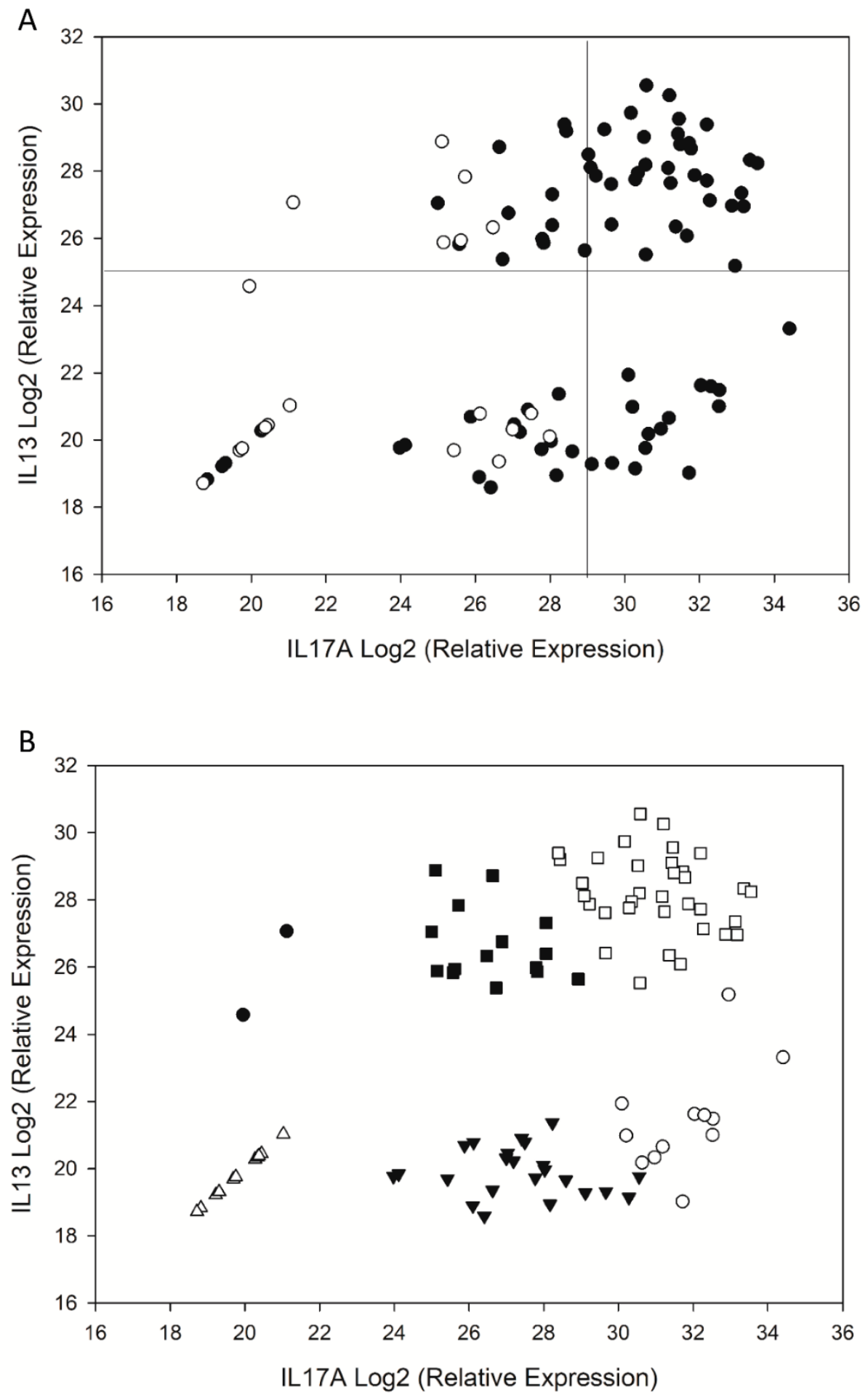

- Cluster1

- Cluster2

$\nabla$ Cluster3

$\triangle$ Cluster4

- Cluster5

$\square \quad$ Cluster6

IL17A Log2 (Relative Expression) 
Figure 4

Z7 High IL-13 mRNA clusters 5+6

Low IL-13 mRNA clusters 2+3+4
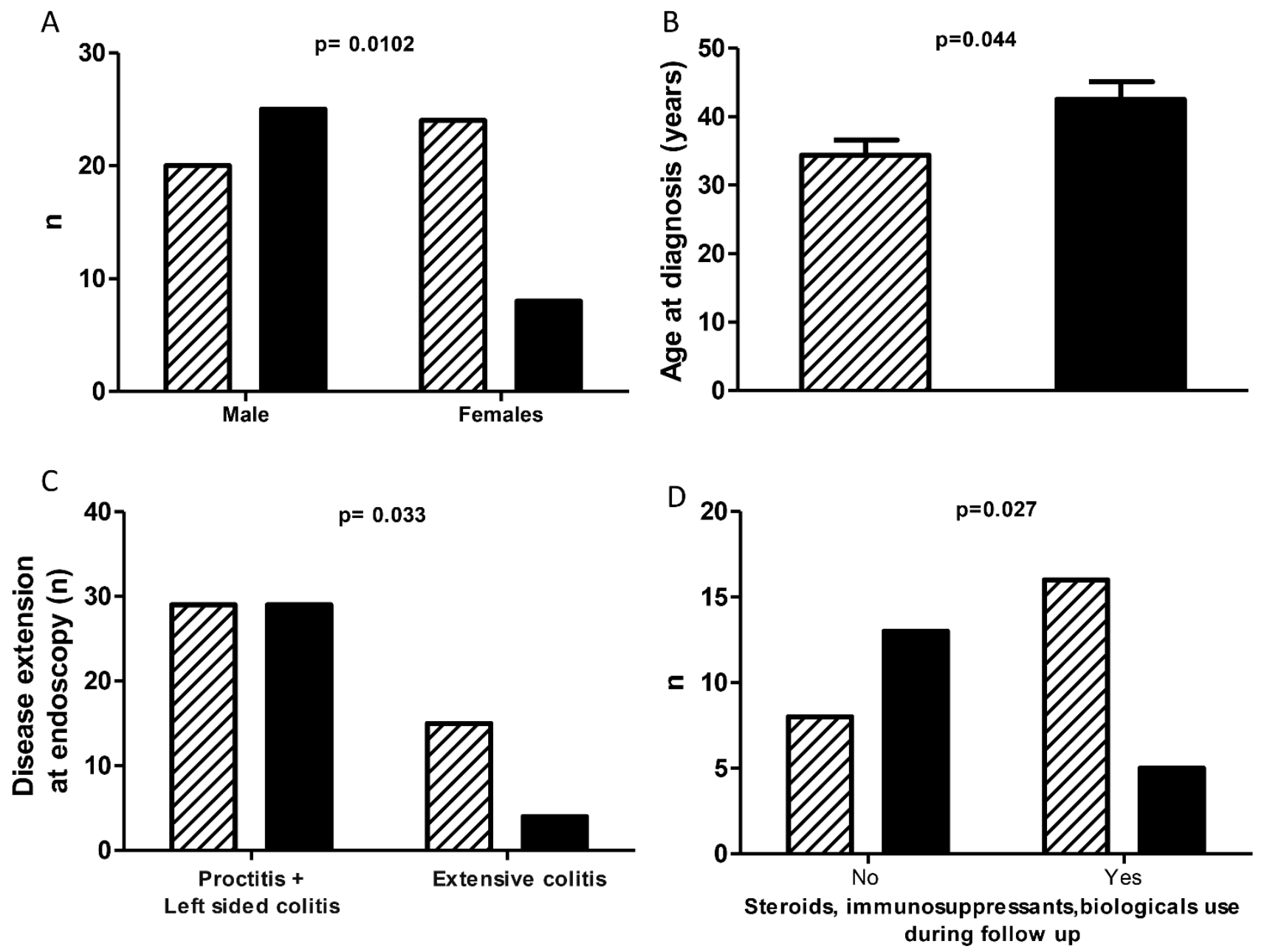


\section{Figure 5}

A

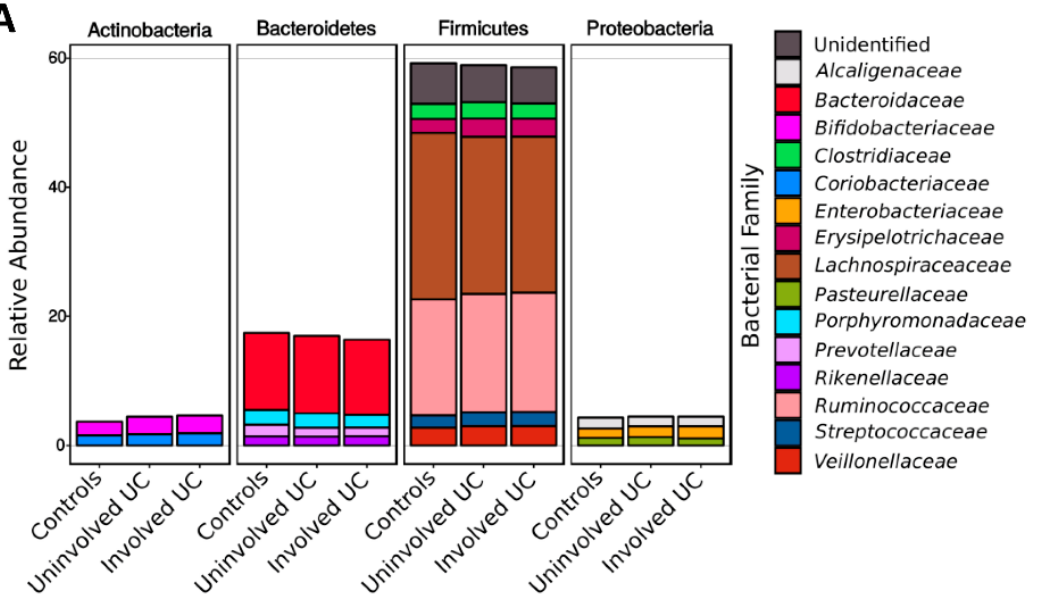

B

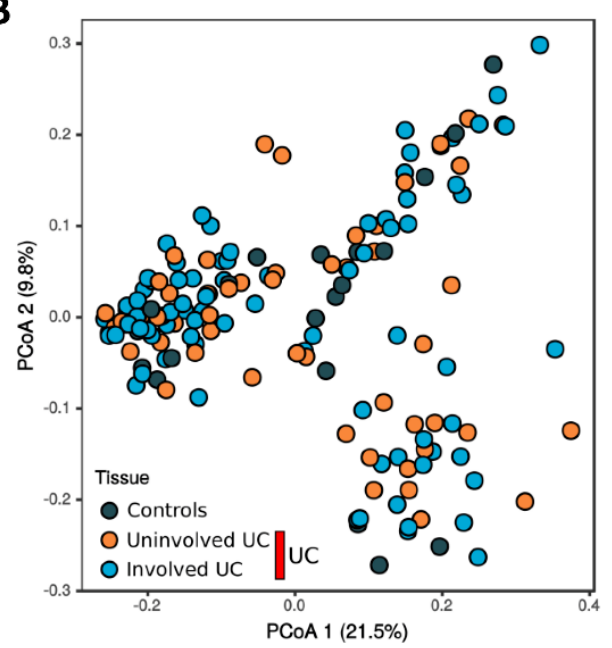

C

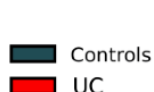

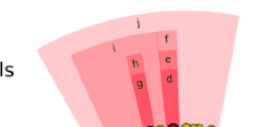

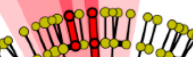
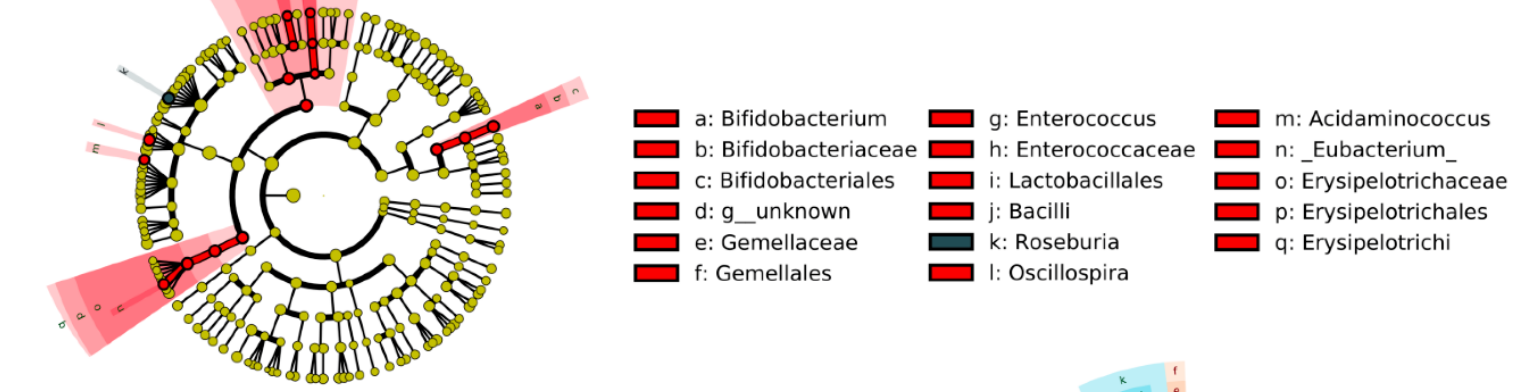
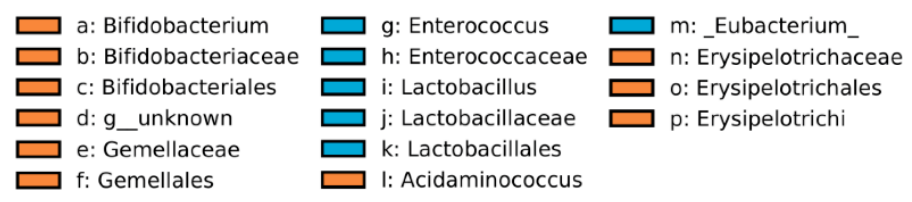

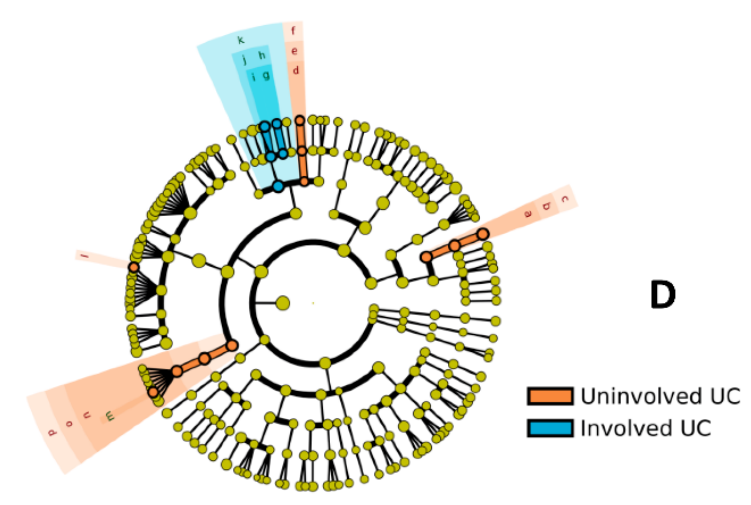




\section{Figure 6}

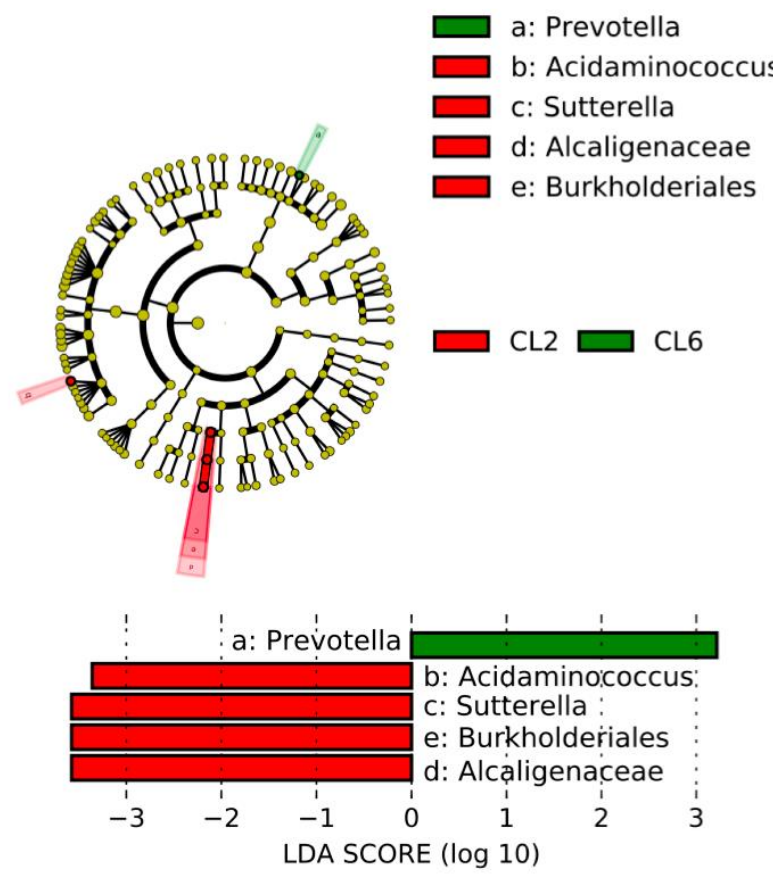

